\title{
Proposal for evaluating the quality of reports of surgical interventions in the treatment of trigeminal neuralgia: the Surgical Trigeminal Neuralgia Score
}

\author{
Harith Akram, F.R.C.S.(Neuro.Surg), ${ }^{1}$ Bilal Mirza, Ph.D.,${ }^{1}$ \\ NeIL Kitchen, F.R.C.S.(SN), ${ }^{1}$ aNd JoAnNa M. ZaKRZEWSKa, F.F.P.M.R.C.A. ${ }^{2}$
}

${ }^{1}$ Victor Horsley Department of Neurosurgery, The National Hospital for Neurology and Neurosurgery, Queen Square; and ${ }^{2}$ Division of Diagnostic, Surgical and Medical Sciences, Eastman Dental Hospital, University College London Hospitals National Health Service Foundation Trust, London, United Kingdom

\begin{abstract}
Object. The aim of this study was to design a checklist with a scoring system for reporting on studies of surgical interventions for trigeminal neuralgia (TN) and to validate it by a review of the recent literature.

Methods. A checklist with a scoring system, the Surgical Trigeminal Neuralgia Score (STNS), was devised partially based on the validated STrengthening the Reporting of OBservational studies in Epidemiology (STROBE) criteria and customized for TN after a literature review and then applied to a series of articles. These articles were identified using a prespecified MEDLINE and Embase search covering the period from 2008 to 2010. Of the 584 articles found, 59 were studies of interventional procedures for TN that fulfilled the inclusion criteria and 56 could be obtained in full. The STNS was then applied independently by 3 of the authors.

Results. The maximum STNS came to 30, and was reliable and reproducible when used by the 3 authors who performed the scoring. The range of scores was 6-23.5, with a mean of 14 for all the journals. The impact factor scores of the journals in which the papers were published ranged from 0 to 4.8 . Twenty-four of the studies were published in the Journal of Neurosurgery or in Neurosurgery. Studies published in neurosurgical journals ranked higher on the STNS scale than those published in nonneurosurgical journals. There was no statistically significant correlation between STNS and impact factors. Stereotactic radiosurgery $(n=25)$ and microvascular decompression $(n=15)$ were the most commonly reported procedures.

The diagnostic criteria were stated in $35 \%$ of the studies, and 4 studies reported subtypes of TN. An increasing number of studies (46\%) used the recommended Kaplan-Meier methodology for pain survival outcomes. The followup period was unclear in 8 studies, and 26 reported follow-ups of more than 5 years. Complications were reported fairly consistently but the temporal course was not always indicated. Direct interview, telephone conversation, and questionnaires were used to measure outcomes. Independent assessment of outcome was only clearly stated in 7 studies. Only 2 studies used the 36-Item Short Form Health Survey to measure quality of life and 4 studies reported on the severity of preoperative pain. The Barrow Neurological Institute pain questionnaire was the most commonly used outcome measure $(\mathrm{n}=13)$, followed by the visual analog scale.

Conclusions. Similar to the STROBE criteria that provide a checklist of items that should be included in reports of observational studies in general, the authors' suggested checklist for the STNS could help editors and reviewers ensure that quality reports are published, and could prove useful for colleagues when reporting their results specifically on the surgical management of TN. It would help the patient and clinicians make a decision about selecting the appropriate neurosurgical procedure.
\end{abstract}

(http://thejns.org/doi/abs/10.3171/2013.6.FOCUS13213)

\section{KeY WordS • facial pain • Gamma Knife • microvascular decompression • Surgical Trigeminal Neuralgia Score $\quad$ - stereotactic radiosurgery $\quad$ - trigeminal neuralgia}

$\mathrm{T}$ RIGEMINAL neuralgia is one of the few chronic neuropathic pain syndromes for which very effective and diverse surgical treatments are available. Recent

\footnotetext{
Abbreviations used in this paper: $\mathrm{BNI}=$ Barrow Neurological Institute; BPI = Brief Pain Inventory; GKS = Gamma Knife surgery; IASP = International Association for the Study of Pain; IF = impact factor; $\mathrm{MVD}=$ microvascular decompression; $\mathrm{QOL}=$ quality of life; RCT $=$ randomized controlled trial; SF-36 = 36-Item Short Form Health Survey; STNS = Surgical Trigeminal Neuralgia Score; STROBE = STrengthening the Reporting of OBservational studies in Epidemiology; TN = trigeminal neuralgia.
}

international guidelines ${ }^{9}$ and systematic reviews s $^{39,46,47}$ identified the shortage of high-quality evidence that can enable patients, physicians, and health policy makers to select the most effective and efficient surgical treatment. Spatz et al ${ }^{37}$ reported that patients found it difficult to choose among surgical treatments for TN for the same reasons. It is essential that high-quality evidence that compares different modalities of treatments is available to provide reliable and balanced selection of a surgical treatment by both patients and health care providers. Wente et al. ${ }^{43}$ analyzed the contents of leading surgical journals and found that only $3 \%$ of articles were reports 


\section{H. Akram et al.}

of RCTs, and of those, $44 \%$ compared different surgical procedures and $56 \%$ compared medical therapies in surgical patients. Of the neurosurgical RCTs, only $52 \%$ were considered to be of good quality. ${ }^{34}$ Similar trends were found in a Cochrane review on neurosurgical interventions for TN. Of 11 RCTs, only 3 were considered applicable in practice.

Importantly, no studies addressed MVD, the most advocated procedure for treatment of TN. ${ }^{46}$ Using evidence from nonrandomized interventions requires very carefully designed trials and reporting. A Health Technology Assessment report by Deeks et al..$^{10}$ provided guidelines for assessment of non-RCTs, which were developed further by Zakrzewska and Lopez ${ }^{47}$ for reporting surgical outcome in TN. The guidelines task force used these, but stipulated that outcomes needed to be assessed by methods independent of the operator and that this needed to be clearly stated. These guidelines have been used by several authors. $., 22,39$

Furthermore, Schriger and Altman, ${ }^{35}$ in their British Medical Journal editorial, suggested that postpublication review of the medical literature was inadequate because letter writing was not considered rewarding, and therefore either the existence or the lack of letters to the editor is not an indicator of "read" status; perhaps many papers remain unread and their results unused. It has been postulated that authors, when challenged about their results (for example when performing systematic reviews), often do not provide sufficient answers, ${ }^{34}$ and this is a significant error; the British Medical Journal issue of January 2012 highlighted how missing data and incomplete reporting can harm patients. ${ }^{17}$ Given the difficulty of performing RCTs of widely accepted surgical techniques, it is increasingly important to ensure that surgical reports are written to uniform standards, allowing results to be used in meta-analyses. ${ }^{5}$ Rughani et al. ${ }^{31}$ showed clearly how different conclusions can be reached when using national databases when compared with small series on TN.

It is increasingly necessary to ensure that all reports are written using a similar structure so that they can be compared; this led to the Consolidated Standards of Reporting Trials (CONSORT) statement in 1996 for the reporting of RCTs, which has now been accepted by all the major journals. ${ }^{2}$ However, not all studies are RCTs, and it has been increasingly recognized that these reports also need a more structured format. This then led to the Statement for Reporting Studies of Diagnostic Accuracy (STARD). ${ }^{3}$ However, this still did not cover all types of studies, and in 2007 a group of epidemiologists, methodologists, statisticians, researchers, and journal editors put forward a proposal for how reporting of observational studies could be improved - this was called the STROBE ${ }^{41}$ statement (http://www.strobe-statement.org/). This statement is now being increasingly endorsed by both medical and surgical journals, and may be the template that could be used for reporting TN studies.

\section{Aim of Study}

The aim of this study was to put forward a checklist and a scoring system in line with the STROBE checklist for quality assessment of papers that report specifically on surgical treatments of $\mathrm{TN}$, to improve the quality of those reports and aid authors and editors.

\section{Methods}

MEDLINE and Embase databases were searched for publications reporting surgical therapies for $\mathrm{TN}$ in the period between January 2008 and January 2010. The search strategy used was based on one used for a Cochrane systematic review ${ }^{46}$ and modified according to the criteria provided.

\section{Inclusion Criteria}

1. Papers reporting primary outcome parameter: effect on pain after surgery.

2. Idiopathic TN.

3. Prospective and retrospective studies.

4. Randomized clinical trials.

5. Language: English. dures.

6. All gasserian ganglion and posterior fossa proce-

7. Redo surgery; that is, separate reports of patients who had 1 prior procedure.

\section{Exclusion Criteria}

1. Technical, anatomical, nontrial experiments, economic, or methodological reports.

2. Reviews, editorials, surveys, guidelines, or commentaries.

3. Case reports including $<5$ patients.

4. Non-TN papers.

5. Symptomatic (secondary) TN or TN with multiple sclerosis. glion.

6. Peripheral treatments distal to the gasserian gan-

Once the papers were identified the titles and abstracts were then read independently by 2 authors (H.A. and J.Z.). If the abstract fulfilled the criteria or there were insufficient data in the abstract, the full papers were obtained and read prior to selection.

A checklist and scoring system, the STNS (Table 1), was devised based on the STROBE statement, the report by Deek et al., ${ }^{10}$ previous recommendations from Zakrzewska and Lopez in 2003, ${ }^{47}$ the TN guidelines committee, and subsequent use of the latter recommendations in other reports. ${ }^{9,39}$ A range of scores from 0 to 30 was then applied to the papers that fulfilled the inclusion criteria, with scores $>25$ being considered high quality. The results were presented at the Society of British Neurological Surgeons' scientific meeting in Leeds in September 2012. Feedback from the discussion was used to refine the scoring system further.

A randomization software program (RandomAllocations Software version 1.0, M. Saghaei, Department of Anesthesia, Isfahan University of Medical Sciences) was used to randomize the papers to 3 equally distributed groups to be scored by 3 of the authors (H.A., B.M., J.Z.). Ten percent of the scored papers were redistributed among the 3 authors, in such a way that no author reviewed the same paper twice, for validation and consis- 


\section{The Surgical Trigeminal Neuralgia Score}

\section{TABLE 1: The STNS combined with STROBE to design a scoring system*}

\begin{tabular}{|c|c|}
\hline Criterion & Score \\
\hline \multicolumn{2}{|l|}{ Title, Abstract, \& Introduction } \\
\hline abstract provides an informative \& balanced summary of what was done \& what was found & 1 \\
\hline \multicolumn{2}{|l|}{ Methods section } \\
\hline presents key elements of study design early in the paper & 1 \\
\hline gives TN diagnostic criteria & 1 \\
\hline uses International Headache Society or IASP criteria & 1 \\
\hline provides a broad description of op technique: e.g., max temp given (RFTC), no. of sites, \& dose provided (by GKS) & 1 \\
\hline sensory assessment done \& any deficits from previous treatments stated & 1 \\
\hline FU through interview, telephone, questionnaire (score 0 for notes only) & 1 \\
\hline if questionnaire is used, is it provided or reference provided? & 1 \\
\hline is it a validated questionnaire? & 1 \\
\hline clearly defines all outcomes, exposures, predictors, potential confounders, \& effect modifiers & 1 \\
\hline describes any efforts to address potential sources of bias, clear statement on use of independent observers & 1 \\
\hline describes all statistical methods, including those used to control for confounding & 1 \\
\hline explains how missing data were addressed, sample size at the start \& at the end, w/ percentage of patients lost to FU stated & 1 \\
\hline \multicolumn{2}{|l|}{ Results section } \\
\hline gives characteristics of study participants (e.g., demographic, clinical, social) & 1 \\
\hline gives characteristics of laterality \& divisions of CN V involved & 1 \\
\hline details of previous op treatments given & 1 \\
\hline summarizes FU time (e.g., average, total amount, range) & 1 \\
\hline FU period of $\geq 12$ mos & 1 \\
\hline states op findings \& failures (MVD) & 1 \\
\hline $\begin{array}{l}\text { reports nos. of outcome events or summary measures over time, reports outcomes separately for complete \& partial pain relief, \& defines } \\
\text { recurrence }\end{array}$ & 1 \\
\hline were the outcomes reported separately in case of a mixed TN cohort? & 1 \\
\hline provides a baseline measure of pain/QOL & 1 \\
\hline provides a KM graph & 1 \\
\hline the KM graph is correctly constructed & 1 \\
\hline provides the exact no. of patients at the end of the KM graph over 3 yrs & 1 \\
\hline reports detailed complications related to CN V & 1 \\
\hline reports detailed complications outside CN V & 1 \\
\hline uses severity \& time scales when reporting complications & 1 \\
\hline reports immediate op complications & 1 \\
\hline reports mortality rate & 1 \\
\hline total & 30 \\
\hline \multicolumn{2}{|l|}{ additional data suggested by STROBE for Discussion section } \\
\hline \multicolumn{2}{|l|}{$\begin{array}{l}\text { discuss limitations of study, taking into account sources of potential bias or imprecision; discuss both direction \& magnitude of any poten- } \\
\text { tial bias }\end{array}$} \\
\hline \multicolumn{2}{|l|}{$\begin{array}{l}\text { give a cautious overall interpretation of results considering objectives, limitations, multiplicity of analyses, results from similar studies, \& } \\
\text { other relevant evidence }\end{array}$} \\
\hline \multicolumn{2}{|l|}{ discuss the generalizability (external validity) of the study results } \\
\hline $\begin{array}{l}\text { give the source of funding \& the role of the funders in the present study \&, if applicable, in the original study on which the present article is } \\
\text { based }\end{array}$ & \\
\hline
\end{tabular}

* $\mathrm{CN}=$ cranial nerve; $\mathrm{FU}=$ follow-up; $\mathrm{KM}=$ Kaplan-Meier; max temp = maximum temperature; $\mathrm{RFTC}=$ radiofrequency thermocoagulation.

tency of data acquisition. In cases of discrepancy the review was discussed between the authors.

The extracted data and scores were entered directly into a Microsoft Excel spreadsheet generated from a Mi- crosoft Access database. The IFs of all the journals in which reports were found were obtained from the Journal Citation Reports (2010), an annual publication by the Healthcare \& Science division of Thomson Reuters. For 


\section{H. Akram et al.}

journals not included in the Journal Citation Reports, an IF of 0 was allocated. The journals were also divided into 2 groups according to the journal's mission statement, readership, and editorial board: 1) mainstream neurosurgical journals; and 2) nonneurosurgical journals.

\section{Statistical Analysis}

When examining the correlation of the scores with the IF, the quality scores were noncontinuous categorical data and did not distribute normally. Therefore nonparametric statistical analysis was performed: the Spearman rank correlation test to assess the correlation between the quality scores and IF, and the unpaired t-test for group comparisons. Given the single comparison decided a priori, the significance level was set at $\mathrm{p}<0.05$.

\section{Results}

There were minor discrepancies between authors on some of the scored items. The most significant of these was regarding the reporting on the baseline measure of pain; an agreement was reached to credit only papers that reported the actual baseline measure of pain and not those that just stated that it was measured. This meant that 4 papers instead of 17 were awarded 1 point in this category. ${ }^{12-14,45}$

\section{Identified Papers}

Fifty-nine of 584 papers fulfilled the inclusion criteria. Fifty-six manuscripts were available for review and manuscripts for 3 papers could not be obtained, because those papers were not indexed in the British Library.

The 56 articles were published in a wide range of journals, from principal neurosurgical journals to periodicals that most neurosurgeons would not access regularly. The IF of the journals cited in the Journal Citation Reports ranged from 0.408 to 4.791 (Table 2). The data extracted from the included studies are shown in Table 3.

\section{Study Design}

Most studies (77\%) were retrospective. There were 3 multicenter studies $(5 \%)$. A structured abstract with clearly stated objectives was provided in $93 \%$ of the studies. Few studies reported on specific parameters that prognosticate outcome-that is, age, operative techniques, type of TN, ${ }^{26,32}$ and endoscopic identification of neurovascular compression. ${ }^{7}$ Several papers reported repeat procedures in relatively small numbers of patients, ${ }^{18,28,40,42}$ whereas others reported them within the context of the whole cohort of patients. In 23 studies patient databases were available, but the means by which the selection of patients was achieved was not stated in most of the studies.

\section{Demographic Data and Diagnostic Criteria}

Sample sizes at the start varied from 4012 in the study by Chen et al. ${ }^{6}$ to 6 in the paper by Ugwuanyi and Kitchen, ${ }^{40}$ with $86 \%$ reporting more than 30 patients. Those reporting the lowest numbers were repeat operations. Most studies provided basic demographic data. In only 20 studies $(35 \%)$ the diagnostic criteria used were reported, of which $13(22.8 \%)$ used diagnostic criteria from the Inter- national Headache Society or the IASP. Only a few studies clearly defined TN according to the Burchiel classification model of Type 1 and Type $2^{11,25,28,32}$ and analyzed results separately in these groups. Others stated they had mixed groups: $18(31.5 \%)$, but only $12(66.6 \%)$ of those reported the outcomes separately. Diagnostic criteria in 1 series were obtained retrospectively based on a series of 40 binomial questions administered by an independent interviewer to patients up to 10 years post-MVD. ${ }^{26}$ Only $4(7 \%)$ reported a baseline level of pain ${ }^{12,13,15,45}$ to which the subsequent postoperative assessments could be made. Statistical methods were provided in 34 studies (59.6\%).

\section{Surgical Procedures}

The most frequently reported procedures were MVD and GKS, and the largest series reported glycerol and novocaine injections into the gasserian ganglion. Operative procedures were well described in most studies, and the number of isocenters and the treatment dose used for GKS were provided in $30(96.7 \%)$ of 31 and $29(93.5 \%)$ of 31 studies, respectively. Reports on MVD procedures provided details of neurovascular compression in 17 (73.9\%) of 23 papers, and only $6(26.1 \%)$ of 23 detailed findings on MRI. Some of the papers reporting on MVD or GKS procedures provided no technical details.

\section{Postoperative Outcomes}

Only 22 papers $(38.5 \%)$ stated the percentage of patients who failed to get any pain relief. Just under half of the studies (26 [45.6\%]) provided a Kaplan-Meier analysis, but only $10(38.4 \%)$ of those 26 studies indicated how many patients were still in the study at the end of that analysis. Table 3 shows that outcome measures were not clearly defined. Complications were consistently reported, but very few studies reported them in relation to time after surgery. Sensory deficit following GKS was reported in half of the studies. The mortality rate was not stated in GKS studies, and it was stated in $20(62.5 \%)$ of the 32 non-GKS studies. Some centers have used both questionnaires and interviews as a means of follow-up, but this was not universal. Only 7 studies $(12.2 \%)$ clearly stated that an independent observer was used to collect outcome data. The most commonly used outcome measure was the BNI scale or some variant of it. The QOL was assessed in 2 studies by using the SF-36.,27 Azar et al. found no other studies in which the SF-36 was used; they also used the BNI scale in their study to make some comparisons. Two studies used the validated BPI..22,23 There was 1 study comparing the cost analysis of Cyberknife (stereotactic radiosurgery) and MVD. ${ }^{38}$

\section{The Scores}

The maximum STNS that can be achieved is 30; of the selected 56 papers included in this analysis, the scores ranged from 6 to 23.5 (Table 2). One of the two lowestscoring papers (scoring 6 each) was published in a journal with an IF of 2.87, whereas the other was published in a journal not indexed by Thomson Reuters. The highestscoring paper, with a score of 23.5 , was published in a journal with an IF of 2.739. Our analysis showed that the 


\section{The Surgical Trigeminal Neuralgia Score}

TABLE 2: The journals publishing the 56 studies, with 2010 IFs and STNS*

\begin{tabular}{|c|c|c|}
\hline Journal & IF & Average Score \\
\hline \multicolumn{3}{|l|}{ mainstream neurosurgery journals w/ published IFs } \\
\hline Clinical Neurology \& Neurosurgery & 1.64 & 19.00 \\
\hline World Neurosurgery 2010 & 0.68 & 18.00 \\
\hline Zentralblatt für Neurochirurgie & 0.95 & 18.00 \\
\hline Journal of Neurology, Neurosurgery \& Psychiatry & 4.79 & 17.50 \\
\hline Neurochirurgie & 0.41 & 16.50 \\
\hline Neurosurgery & 3.30 & 16.35 \\
\hline Neurosurgical Review & 2.26 & 16.00 \\
\hline Journal of Neurosurgery & 2.74 & 15.60 \\
\hline Canadian Journal of Neurological Sciences & 1.18 & 15.50 \\
\hline Journal of the Korean Neurosurgical Society & 0.61 & 14.50 \\
\hline British Journal of Neurosurgery & 0.97 & 14.25 \\
\hline Acta Neurochirurgica & 1.33 & 13.67 \\
\hline Neurosurgical Focus & 2.35 & 13.00 \\
\hline Stereotactic \& Functional Neurosurgery & 1.88 & 13.00 \\
\hline Surgical Neurology & 1.26 & 12.00 \\
\hline \multicolumn{3}{|l|}{ neurosurgery journals w/ no published IFs } \\
\hline Egyptian Journal of Neurology, Psychiatry and Neurosurgery & NA & 10.50 \\
\hline Pan Arab Journal of Neurosurgery & NA & 10.50 \\
\hline Progress in Neurological Surgery & NA & 7.00 \\
\hline Rawal Medical Journal & NA & 7.00 \\
\hline \multicolumn{3}{|l|}{ nonneurosurgery journals } \\
\hline International Journal of Radiation Oncology Biology and Physics & 4.50 & 20.25 \\
\hline Head \& Face Medicine & 1.04 & 16.00 \\
\hline Neurology India & 0.83 & 14.50 \\
\hline Clinical Journal of Pain & 3.11 & 14.00 \\
\hline Neurological Sciences & 1.22 & 13.00 \\
\hline Cell Biochemistry and Biophysics & 4.31 & 11.50 \\
\hline Journal of Neuroimaging & 1.29 & 10.50 \\
\hline Technology in Cancer Research and Treatment & 1.81 & 9.00 \\
\hline Journal of Clinical Neuroscience & 1.17 & 8.50 \\
\hline Neuroradiology & 2.87 & 6.00 \\
\hline
\end{tabular}

* NA = not applicable.

quality score of the reports and the IF of the journals in which they appeared did not correlate (Spearman rank correlation, $\rho=0.213$; 2-sided $p=0.11$ ).

We used the principal neurosurgical journals with published IFs (Table 2), in which the median STNS was 15.6 (interquartile range 12-19) and the mean was 15.52, and compared them with all the other journals grouped together, with a median STNS of 10.5 (range 6-20.25) and a mean of 11.3. The papers reported in the principal neurosurgical journals had a very significantly higher mean STNS when compared with the other journals (unpaired 2-tailed t-test, $\mathrm{p}=0.0012$ ). There was no significant difference between the IFs of the principal neurosurgical journals and those of the other journals.

\section{Discussion and Recommendations}

To assess the quality of reporting of surgical interven- tions for TN we devised a checklist and scoring system,

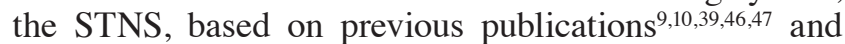
the STROBE statement. The STNS showed that reporting is variable and inconsistent. The scores were higher in reports from neurosurgical journals when compared with other journals. Some studies were published in highIF journals that we assume were not routinely accessed by neurosurgeons, and the quality of reporting in these was inconsistent. Patient-related outcome measures were poorly reported.

Thus, there is a need to improve the quality of neurosurgical reporting; Kiehna et al. ${ }^{19}$ have also shown that results of intracranial neurosurgery RCTs in the principal neurosurgical journals are of a lower standard than in major medical journals. It has been shown that standardized checklists for assessing neurosurgical RCTs could be reliably used by reviewers of different experience levels and 
H. Akram et al.

TABLE 3: Data extracted from the 56 included studies*

\begin{tabular}{|c|c|}
\hline Characteristic & No. $(\%)$ \\
\hline \multicolumn{2}{|l|}{ overall characteristics } \\
\hline abstract in a structured format & $52(93)$ \\
\hline prospective design & $10(18)$ \\
\hline retrospective design & $43(77)$ \\
\hline study design unclear & $3(5)$ \\
\hline \multicolumn{2}{|l|}{ study population } \\
\hline presence of basic demographic data & $49(87)$ \\
\hline diagnostic criteria clearly stated & $20(36)$ \\
\hline \multicolumn{2}{|l|}{ details of FU method stated } \\
\hline interview & $5(9)$ \\
\hline questionnaire & $19(34)$ \\
\hline telephone & $4(7)$ \\
\hline interview \& questionnaire & $11(20)$ \\
\hline various & $2(4)$ \\
\hline not stated & $15(27)$ \\
\hline \multicolumn{2}{|l|}{ type of questionnaire used $\dagger$} \\
\hline BNI scale & $13(46)$ \\
\hline other & $13(46)$ \\
\hline BNI scale, VAS & $1(4)$ \\
\hline BNI, VAS, SF-36 & $1(4)$ \\
\hline \multicolumn{2}{|l|}{ definitions \& outcome measures } \\
\hline primary outcome measures defined (complete \& partial pain relief) & $32(57)$ \\
\hline report outcomes separately for complete \& partial pain relief & $30(54)$ \\
\hline recurrence defined (minor \& major) & $27(48)$ \\
\hline preop pain levels reported & $4(7)$ \\
\hline \multicolumn{2}{|l|}{ sensory assessment } \\
\hline not reported & $27(50)$ \\
\hline done postop & $21(38)$ \\
\hline done preop & $4(7)$ \\
\hline done pre- \& postop & $4(7)$ \\
\hline \multicolumn{2}{|l|}{ patients treated more than once } \\
\hline $0 \%$ & $2(4)$ \\
\hline$<10 \%$ & $10(18)$ \\
\hline$\geq 10 \%$ & $22(39)$ \\
\hline unclear & $21(38)$ \\
\hline \multicolumn{2}{|l|}{ sample size \& length of FU } \\
\hline sample size at start of $\mathrm{FU}<30$ patients & $8(14)$ \\
\hline sample size at start of $\mathrm{FU} \geq 30$ patients & $48(86)$ \\
\hline FU $1-5$ yrs & $22(39)$ \\
\hline FU $>5$ yrs & $26(46)$ \\
\hline FU period unclear & $8(14)$ \\
\hline \multicolumn{2}{|l|}{ type of intervention } \\
\hline SRS & $25(45)$ \\
\hline MVD & $15(27)$ \\
\hline MVD \& SRS & $3(5)$ \\
\hline PBC & $3(5)$ \\
\hline RFTC & $3(5)$ \\
\hline MVD, PGI, RFTC & $1(2)$ \\
\hline
\end{tabular}

(continued) 


\section{The Surgical Trigeminal Neuralgia Score}

TABLE 3: Data extracted from the 56 included studies* (continued)

\begin{tabular}{lc}
\hline \multicolumn{1}{c}{ Characteristic } & No. (\%) \\
\hline $\begin{array}{l}\text { type of intervention (continued) } \\
\text { nerve combing }\end{array}$ & $1(2)$ \\
PBC, MVD & $1(2)$ \\
redo MVD & $1(2)$ \\
PGI & $1(2)$ \\
PBC, PGI & $1(2)$ \\
MVD, RFTC, PGI, SRS & $1(2)$ \\
$\%$ of patients lost to FU & $19(34)$ \\
$0 \%$ & $15(27)$ \\
$<10 \%$ & $5(9)$ \\
$10-20 \%$ & $2(4)$ \\
$>20 \%$ & $15(27)$ \\
unclear & \\
morbidity \& mortality & $19(34)$ \\
mortality rate stated & $26(46)$ \\
reports immediate op complications & $46(82)$ \\
reports detailed complications of CN V & $43(77)$ \\
reports details of complications outside CN V & $20(36)$ \\
reports complications in relation to time \& severity & $26(46)$ \\
uses KM for pain relief outcomes &
\end{tabular}

thus can improve quality. This is important because there is a risk that readers may underestimate or even ignore the role of poor design or reporting when deriving conclusions from reports published in more recognized journals or in journals with a higher IF. It is possible that journals that do not routinely publish reports on TN are less likely to have the relevant expertise, and so may not be as rigorous in the reviewing process. This explains why poorly scored reports were published in high-IF nonneurosurgical journals.

Our study showed that preoperative levels of pain, presence of sensory changes, and impact of the pain on the QOL were not consistently reported. It is essential to measure baseline pain and its impact preoperatively to evaluate outcomes because this is often missing, even in the field of pain medicine. ${ }^{24}$ Some authors, ${ }^{11,25,26,44}$ realizing the importance of baseline assessments, attempted to estimate pain preoperatively by interviewing patients postoperatively; in some instances this was done 10 years after the intervention was performed. Another problem when assessing pain outcomes is that $\mathrm{TN}$ is episodic, so it is not just the pain intensity that is important but also the frequency and number of branches involved, which led Degn and Brennum ${ }^{11}$ to suggest a pain vector that takes this into account (http://tn.neurokirurgi.info).

It is now established that a range of outcome measures from different perspectives needs to be used; for example, patient-reported outcomes, independent assessments such as those provided by MRI, and clinical events and therapeutic outcomes such as length of hospitaliza- tion, treatment failure, and repeat surgery. The SF-36, the most widely used generic patient-related outcome measure, was used both pre- and postoperatively by Azar et al. ${ }^{1}$ and Pan et al. ${ }^{27}$ However, Garratt, ${ }^{16}$ when commenting on the SF-36, argued that there was an urgent need for "an appropriate and standardised application of measures that include aspects of health and quality of life, and end points that are of genuine importance to patients." There is ample evidence that outcome measures, if not assessed in an independent, blinded way, are subject to bias and are associated with significantly larger positive treatment effects than blinded outcome assessments. ${ }^{29}$

Recently the IASP ${ }^{14}$ put forward suggestions for a variety of outcome scales for patients with chronic pain, some of which are used in TN. Lee et al. ${ }^{20}$ noted that these requirements have extended the recommended BPI to take into account the impact that $\mathrm{TN}$ specifically has on daily living. They have validated its use as a screening tool, but its usefulness for monitoring outcomes over time remains to be established. This is a significant step forward because QOL and impact on daily living are crucial outcome measures, because in some patients pain relief is achieved at the cost of anesthesia dolorosa or loss of hearing; in a musician, for example, this can render the QOL worse than prior to the operation. It is clear that complications and their time course directly influence the QOL, which necessitates a priori risk-balancing before selecting an appropriate surgical procedure.

Questionnaire development and testing is a complex 


\section{H. Akram et al.}

process, as Lee et al..$^{20}$ have illustrated. Once questionnaires have been tested and shown to be valid, reliable, and reproducible, they cannot be altered by addition or subtraction of items, as has been done by some authors. ${ }^{21,33}$ Rogers et al.$^{30}$ devised the BNI scoring system, which combined pain intensity and the use of medication. It was not specified how this scale was to be used, for example, from data in the medical records or from patients' completed forms. This particular scale was used in several studies. Some reported using it prior to surgery and stated that the patients' BNI scores were Grade IV or $\mathrm{V}, 12,15,27,36,45$ showing that patients who underwent surgery had intractable pain. Because pain relief after GKS is not immediate, patients remain on medication for several months. Some patients may become reluctant to stop their medication for fear of pain recurrence, and so would provide lower scores on the BNI scale than would be expected. The BNI Facial Numbness Scale was applied by others..$^{8,15}$ It is a subjective assessment by the patient, which may not always correlate with neurophysiological testing, a more independent assessment.

The STROBE statement emphasizes the need to define all outcome measures and to provide details of the methods of assessment. We would propose the use of the BPI-Facial as the essential outcome measure because it measures not only intensity of pain but also the impact of the disease both on general activities of daily living and other specific activities such as the ability to eat.

When reviewing papers it may be useful to use the guidelines provided by STROBE for the discussion, which are shown in Table 1, but which were not used to generate a score.

\section{Proposal and Conclusions}

Our recommendations are as follows. 1) The STNS now needs to be used by authors, journal editors, and reviewers as a checklist when reporting on surgical outcomes in patients with TN. 2) A similar study to ours can be repeated in the future once the STNS is in use to determine whether its widespread use can improve the reporting and hence the generalizability of surgical interventions for TN. Improved generalizability of data could help guide patients, health care professionals, and policy makers in making decisions on the most effective treatments.

\section{Disclosure}

Dr. Zakrzewska undertook this work at University College London/University College London Hospitals Trust, and received a portion of funding from the Department of Health's National Institute for Health Research Biomedical Research Centre funding scheme.

Author contributions to the study and manuscript preparation include the following. Conception and design: Akram, Zakrzewska. Acquisition of data: Akram, Mirza, Zakrzewska. Analysis and interpretation of data: Akram, Mirza, Zakrzewska. Drafting the article: all authors. Critically revising the article: Kitchen, Zakrzewska. Reviewed submitted version of manuscript: Kitchen, Zakrzewska. Statistical analysis: Akram, Mirza. Administrative/technical/material support: Akram.

\section{References}

1. Azar M, Yahyavi ST, Bitaraf MA, Gazik FK, Allahverdi M,
Shahbazi S, et al: Gamma knife radiosurgery in patients with trigeminal neuralgia: quality of life, outcomes, and complications. Clin Neurol Neurosurg 111:174-178, 2009

2. Begg C, Cho M, Eastwood S, Horton R, Moher D, Olkin I, et al: Improving the quality of reporting of randomized controlled trials. The CONSORT statement. JAMA 276:637639, 1996

3. Bossuyt PM, Reitsma JB, Bruns DE, Gatsonis CA, Glasziou PP, Irwig LM, et al: The STARD statement for reporting studies of diagnostic accuracy: explanation and elaboration. Croat Med J 44:639-650, 2003

4. Chakravarthi PS, Ghanta R, Kattimani V: Microvascular decompression treatment for trigeminal neuralgia. J Craniofac Surg 22:894-898, 2011

5. Chan AW: Out of sight but not out of mind: how to search for unpublished clinical trial evidence. BMJ 344:d8013, 2012

6. Chen L, Xu M, Zou Y: Treatment of trigeminal neuralgia with percutaneous glycerol injection into Meckel's cavity: experience in 4012 patients. Cell Biochem Biophys 58:85-89, 2010

7. Chen MJ, Zhang WJ, Yang C, Wu YQ, Zhang ZY, Wang Y: Endoscopic neurovascular perspective in microvascular decompression of trigeminal neuralgia. J Craniomaxillofac Surg 36:456-461, 2008

8. Cheuk AV, Chin LS, Petit JH, Herman JM, Fang HB, Regine WF: Gamma knife surgery for trigeminal neuralgia: outcome, imaging, and brainstem correlates. Int J Radiat Oncol Biol Phys 60:537-541, 2004

9. Cruccu G, Gronseth G, Alksne J, Argoff C, Brainin M, Burchiel $\mathrm{K}$, et al: AAN-EFNS guidelines on trigeminal neuralgia management. Eur J Neurol 15:1013-1028, 2008

10. Deeks JJ, Dinnes J, D’Amico R, Sowden AJ, Sakarovitch C, Song F, et al: Evaluating non-randomised intervention studies. Health Technol Assess 7:iii-x, 1-173, 2003

11. Degn J, Brennum J: Surgical treatment of trigeminal neuralgia. Results from the use of glycerol injection, microvascular decompression, and rhizotomia. Acta Neurochir (Wien) 152: 2125-2132, 2010

12. Dellaretti M, Reyns N, Touzet G, Sarrazin T, Dubois F, Lartigau E, et al: Clinical outcomes after Gamma Knife surgery for idiopathic trigeminal neuralgia: review of 76 consecutive cases. J Neurosurg 109 Suppl:173-178, 2008

13. Dhople AA, Adams JR, Maggio WW, Naqvi SA, Regine WF, Kwok Y: Long-term outcomes of Gamma Knife radiosurgery for classic trigeminal neuralgia: implications of treatment and critical review of the literature. Clinical article. J Neurosurg 111:351-358, 2009

14. Dworkin RH, Turk DC, Farrar JT, Haythornthwaite JA, Jensen MP, Katz NP, et al: Core outcome measures for chronic pain clinical trials: IMMPACT recommendations. Pain 113:9-19, 2005

15. Fariselli L, Marras C, De Santis M, Marchetti M, Milanesi I, Broggi G: CyberKnife radiosurgery as a first treatment for idiopathic trigeminal neuralgia. Neurosurgery 64 (2 Suppl): A96-A101, 2009

16. Garratt A: Patient reported outcome measures in trials. BMJ 338:a2597, 2009

17. Godlee F, Wager E: Research misconduct in the UK. BMJ 344:d8357, 2012

18. Han I, Shin D, Chang J, Kim K, Chang J, Huh R, et al: Effect of various surgical modalities in recurrent or persistent trigeminal neuralgia. Stereotact Funct Neurosurg 88:156162,2010

19. Kiehna EN, Starke RM, Pouratian N, Dumont AS: Standards for reporting randomized controlled trials in neurosurgery. A review. J Neurosurg 114:280-285, 2011

20. Lee JY, Chen HI, Urban C, Hojat A, Church E, Xie SX, et al: Development of and psychometric testing for the Brief Pain Inventory-Facial in patients with facial pain syndromes. Clinical article. J Neurosurg 113:516-523, 2010 


\section{The Surgical Trigeminal Neuralgia Score}

21. Linskey ME, Ratanatharathorn V, Peñagaricano J: A prospective cohort study of microvascular decompression and Gamma Knife surgery in patients with trigeminal neuralgia. J Neurosurg 109 Suppl:160-172, 2008

22. Little AS, Shetter AG, Shetter ME, Bay C, Rogers CL: Longterm pain response and quality of life in patients with typical trigeminal neuralgia treated with gamma knife stereotactic radiosurgery. Neurosurgery 63:915-924, 2008

23. Little AS, Shetter AG, Shetter ME, Kakarla UK, Rogers CL: Salvage gamma knife stereotactic radiosurgery for surgically refractory trigeminal neuralgia. Int J Radiat Oncol Biol Phys 74:522-527, 2009

24. Loeser JD: Relieving pain in America. Clin J Pain 28:185186, 2012

25. Miller JP, Acar F, Burchiel KJ: Classification of trigeminal neuralgia: clinical, therapeutic, and prognostic implications in a series of 144 patients undergoing microvascular decompression. Clinical article. J Neurosurg 111:1231-1234, 2009

26. Miller JP, Magill ST, Acar F, Burchiel KJ: Predictors of longterm success after microvascular decompression for trigeminal neuralgia. Clinical article. J Neurosurg 110:620-626, 2009

27. Pan HC, Sheehan J, Huang CF, Sheu ML, Yang DY, Chiu WT: Quality-of-life outcomes after Gamma Knife surgery for trigeminal neuralgia. Clinical article. J Neurosurg 113 Suppl: 191-198, 2010

28. Pollock BE, Stein KJ: Surgical management of trigeminal neuralgia patients with recurrent or persistent pain despite three or more prior operations. World Neurosurg 73:523528,2010

29. Poolman RW, Struijs PA, Krips R, Sierevelt IN, Marti RK, Farrokhyar F, et al: Reporting of outcomes in orthopaedic randomized trials: does blinding of outcome assessors matter? J Bone Joint Surg Am 89:550-558, 2007

30. Rogers CL, Shetter AG, Fiedler JA, Smith KA, Han PP, Speiser BL: Gamma knife radiosurgery for trigeminal neuralgia: the initial experience of The Barrow Neurological Institute. Int J Radiat Oncol Biol Phys 47:1013-1019, 2000

31. Rughani AI, Dumont TM, Lin CT, Tranmer BI, Horgan MA: Safety of microvascular decompression for trigeminal neuralgia in the elderly. Clinical article. J Neurosurg 115:202-209, 2011

32. Sandell T, Eide PK: Effect of microvascular decompression in trigeminal neuralgia patients with or without constant pain. Neurosurgery 63:93-100, 2008

33. Sarsam Z, Garcia-Fiñana M, Nurmikko TJ, Varma TRK, Eldridge P: The long-term outcome of microvascular decompression for trigeminal neuralgia. Br J Neurosurg 24:18-25, 2010

34. Scholler K, Licht S, Tonn JC, Uhl E: Randomized controlled trials in neurosurgery-how good are we? Acta Neurochir (Wien) 151:519-527, 2009

35. Schriger DL, Altman DG: Inadequate post-publication review of medical research. BMJ 341:c3803, 2010
36. Sheehan JP, Ray DK, Monteith S, Yen CP, Lesnick J, Kersh $\mathrm{R}$, et al: Gamma Knife radiosurgery for trigeminal neuralgia: the impact of magnetic resonance imaging-detected vascular impingement of the affected nerve. Clinical article. J Neurosurg 113:53-58, 2010

37. Spatz AL, Zakrzewska JM, Kay EJ: Decision analysis of medical and surgical treatments for trigeminal neuralgia: how patient evaluations of benefits and risks affect the utility of treatment decisions. Pain 131:302-310, 2007

38. Tarricone R, Aguzzi G, Musi F, Fariselli L, Casasco A: Costeffectiveness analysis for trigeminal neuralgia: Cyberknife vs microvascular decompression. Neuropsychiatr Dis Treat 4: 647-652, 2008

39. Tatli M, Satici O, Kanpolat Y, Sindou M: Various surgical modalities for trigeminal neuralgia: literature study of respective long-term outcomes. Acta Neurochir (Wien) 150:243-255, 2008

40. Ugwuanyi UC, Kitchen ND: The operative findings in re-do microvascular decompression for recurrent trigeminal neuralgia. Br J Neurosurg 24:26-30, 2010

41. von Elm E, Altman DG, Egger M, Pocock SJ, Gøtzsche PC, Vandenbroucke JP: The Strengthening the Reporting of Observational Studies in Epidemiology (STROBE) statement: guidelines for reporting observational studies. Prev Med 45:247251,2007

42. Wang L, Zhao ZW, Qin HZ, Li WT, Zhang H, Zong JH, et al: Repeat gamma knife radiosurgery for recurrent or refractory trigeminal neuralgia. Neurol India 56:36-41, 2008

43. Wente MN, Seiler CM, Uhl W, Büchler MW: Perspectives of evidence-based surgery. Dig Surg 20:263-269, 2003

44. Zacest AC, Magill ST, Miller J, Burchiel KJ: Preoperative magnetic resonance imaging in Type 2 trigeminal neuralgia. Clinical article. J Neurosurg 113:511-515, 2010

45. Zahra H, Teh BS, Paulino AC, Yoshor D, Trask T, Baskin D, et al: Stereotactic radiosurgery for trigeminal neuralgia utilizing the BrainLAB Novalis system. Technol Cancer Res Treat 8:407-412, 2009

46. Zakrzewska JM, Akram H: Neurosurgical interventions for the treatment of classical trigeminal neuralgia. Cochrane Database Syst Rev 9:CD007312, 2011

47. Zakrzewska JM, Lopez BC: Quality of reporting in evaluations of surgical treatment of trigeminal neuralgia: recommendations for future reports. Neurosurgery 53:110-122, 2003

Manuscript submitted May 9, 2013.

Accepted June 6, 2013.

Please include this information when citing this paper: DOI: 10.3171/2013.6.FOCUS13213.

Address correspondence to: Harith Akram, F.R.C.S.(Neuro. Surg), Victor Horsley Department of Neurosurgery, The National Hospital for Neurology \& Neurosurgery, Queen Square, London WC1N 3BG, United Kingdom. email: harith.akram@ doctors.org.uk. 